\title{
Mathematical Model Analysis for Mass and Rates of Woodchip IR Drying
}

\author{
Pryce M.J.*, Cheneler D., Martin A. and Aiouache F.* \\ *Authors for correspondence \\ Department of Engineering \\ Lancaster University, \\ Bailrigg, Lancaster \\ United Kingdom \\ f.aiouache@lancaster.ac.uk, m.pryce1@lancaster.ac.uk
}

\begin{abstract}
The production of woodchip biomass, by means of drying, is of importance with respect to environmental concerns. This has been highlighted by reports of carbon production through utility usage of commercial sites, where drying is often among the most energy intensive operations within industrial processes. It is therefore crucial to dry wood in efficient way in order to derive high quality products and increase end use process efficiency. A key component for dry fuel suppliers is the moisture content of the woodchip product. Halogen (infrared) drying is the foremost method used on site to measure moisture content of wood fuel for supply, as this takes less time, a smaller sample size and less human interaction, in comparison with convective drying. This study investigated the drying behaviour of static woodchip fuel using an infrared source at temperatures ranging from 50 to $80^{\circ} \mathrm{C}$ and atmospheric pressure. With the longest drying time (time until a rate of $0.001 \mathrm{~g}$ per 99 seconds is reached) of just over three hours and the shortest under an hour and a half. Mathematical models of the drying rates were determined through statistical analysis and the significance of the initial drying periods relevant to rates of falling and constant profiles were analysed for the different temperatures. Statistically the model with the best fit at the temperatures measured was a diffusion model with 6 exponential terms and coefficients with the SSE value $0.2424, \mathrm{R}^{2}$ of 0.9989 and RMSE of less than 0.009 . Models with 4 coefficients were also able to fit the data well with SSE values of below 0.03. Differentiating the resulting equations of fit at constant temperature resulted in models for the rate of mass lost over time.
\end{abstract}

Keywords: Drying, Energy and Environmental Systems, Mass Transfer, Materials Processing, Radiation

NOMENCLATURE

\begin{tabular}{lll} 
M & {$[\mathrm{kg}]$} & mass \\
X (DB) & {$[-]$} & Moisture Content \\
W & {$\left[\mathrm{g} \mathrm{s}^{-1} \mathrm{M}^{-1}\right]$} & Rate of Drying \\
$\mathrm{D}$ & & Diffusion Coefficient \\
$\mathrm{L}$ & {$[\mathrm{m}]$} & Length \\
$\mathrm{C}$ & & Concentration \\
$\mathrm{J}$ & & Flux \\
$\mathrm{t}$ & {$[\mathrm{s}]$} & Time \\
$\mathrm{T}$ & {$\left[{ }^{\circ} \mathrm{C}\right]$} & Temperature \\
MR & {$[-]$} & Moisture ratio \\
\hline
\end{tabular}

\begin{tabular}{lll}
\hline A & {$\left[\mathrm{m}^{2}\right]$} & Surface Area \\
a,b,c,d,f,g, & {$[-]$} & Model Dependent Coefficients \\
Special Characters & & \\
$\alpha, \beta, \gamma$ & {$[-]$} & Model Dependent Coefficients \\
Subscripts & & \\
e & Equilibrium/Final \\
0 & & Initial \\
i & Species i/Result i \\
D & Drying \\
\hline
\end{tabular}

\section{Industrial Relevance}

This paper investigates the drying behaviour of woodchip under an infrared (IR) source. In the biomass industry this procedure is used as a quick method to provide the moisture percentage content for quality control. From the same sample at different temperatures, moisture readings have been taken and the consistency of these results were assessed. In partnership with industry, the resulting drying models are of a value for incorporation into advanced computational fluid dynamics codes that simulate existing industrial dryers of woodchip.

\section{Introduction}

IR drying by a halogen device is a mature method for onsite measurement of moisture content of woodchip biomass. IR based drying heats molecules through radiative heat transfer which reduces heat transferred resistances of conventional drying by convective and conductive heat transfers to solid materials. IR drying procedures are therefore faster and requires a smaller sample size, greater control over conditions and less human interaction. 
Woodchip technology consists of processing wood through three main stages (i) sourcing timber, (ii) chipping of logs, and (iii) drying the chipped wood. With the calorific $(\mathrm{MJ} / \mathrm{kg}$ ) value of woodchip linearly proportional to the moisture content of wood[1], drying wet chip is necessary to achieve greater combustion, per weight of biomass. Biomass boiler are therefore rated to a defined moisture content of wood feed. Other benefits of drying include quality, characterisation of wood allowing comparison between various origins, reduced energy consumption for transport and storage, driven by a reduction in mass and fungal build up. On the other hand, the fuel sourced from woodchip is generally in higher demand over the winter period when the supply faces a higher moisture content due to both the colder and wetter weathers. Therefore, in winter months, drying is required not only to improve the fuels quality but preserve and keep a consistent supply.

That said drying is an energy intensive unit operation and is seen as a significant source of $\mathrm{CO}_{2}$ emissions. This is true for woodchip manufacturing, as for Bowland Bioenergy, the company partner for this project, the drying process uses over $81 \%$ of the onsite electricity and the only greater source of $\mathrm{tCO}_{2} \mathrm{e}$ on site is liquid fuel for vehicles and generators.

IR drying of foodstuffs has been widely studied. The thin layer models were applied to fit the drying behaviours of carrots [2]barley [3], spinach[4] and banana [5], to name a few. IR drying has been however less investigated amongst inedible material, and among the few examples reported in literature are studies on gypsum[6] and plaster of paris [7]. Erbay and Icer reviewed various studies on the thin layer drying of foods[8] and found that of all drying characterisation of foodstuffs over $11 \%$ of all studies used some form of IR drying.

In the IR drying the driving force is a partial pressure gradient produced by the temperature difference between water vapour and ambient air. This pressure difference between the surrounding air and the material forces moisture out of pores and into the air.

The following section describes the principles of mathematical modelling of IR drying. The third section describes the drying methods and procedures used and the latter sections describe the analysis of results, discussions and a conclusion.

\section{Mathematical Modelling of IR Drying}

The falling rate period of the drying shows the behaviour of moisture diffusing through material. After an initial evaporation of the surface moisture, the rate of mass loss decreases as moisture has to diffuse from the centre of the material to the surface of the solid, obeying Fick's law of mass transfer;

$$
\mathrm{J}_{\mathrm{i}}=-\mathrm{D} \frac{\mathrm{dC}}{\mathrm{dx}}
$$

Where the mass flux $\mathrm{J}_{\mathrm{i}}$ is defined by the diffusion coefficient, $\mathrm{D}$, and the concentration gradient, $\frac{\mathrm{dC}}{\mathrm{dx}}$. Transforming the second Fick's law [9], by considering the rate of accumulation of a substrate in a control volume, the resulting relationship is;

$$
\frac{d C_{i}}{d t}=\frac{d}{d x}\left(D \frac{d C_{i}}{d x}\right)
$$

Expressing the ratio of moisture, $\mathrm{MR}$, within the woodchip at time $\mathrm{t}$ from the current, initial and final masses $\mathrm{M}$;

$$
M R=\frac{M_{t}-M_{e}}{M_{0}-M_{e}}
$$

Using the assumptions of:

- symmetric uniform distribution of moisture within the initial sample.

- Symmetric mass transfer respect to the centre of the solid.

- Constant diffusion coefficient.

- Negligible shrinkage.

- Instantaneous evaporation at the surface (i.e. the concentration on the face from which the diffusing substance emerges is maintained at effectively zero).

- Steady state conditions for the finite interval of time is defined after IR drying at $105^{\circ} \mathrm{C}[10]$.

The drying rate is defined as the amount of moisture removed from the dried material per unit time, and unit surface area [11];

$$
W_{D}=\frac{-M_{e} d X}{A d t}
$$


For a constant surface area, $A$, and mass of dried solid, $\mathrm{M}_{\mathrm{e}}$, the rate, $\mathrm{W}_{\mathrm{D}}$, can therefore be determined through differentiation of the moisture ratio over time.

$$
W_{D} A=\left|\left(M_{0}-M_{e}\right)\left(\frac{d M R}{d t}\right)\right|=\left|\frac{d_{t}}{d t}\right|
$$

\section{Materials and Method}

The woodchip was supplied by Bowland Bioenergy Ltd. A random sample of woodchip was sieved using circular holed sieves as per BSI wood fuel testing standards [12]. This wood had been externally stored as logs and chipped, with no prior drying other than natural weathering. A sample of $20 \mathrm{~g} \pm 5 \mathrm{~g}$, with any bark chippings removed, was taken from sieve rating $6 \mathrm{~mm}$ with a $8 \mathrm{~mm}$ sieve size above. The sample was then soaked in deionised water for 12 hours a sub sample of $\approx 10 \mathrm{~g}$ was taken for use within the drying procedure.

\section{Drying Procedure}

The halogen drier had a weight accuracy of $\pm 0.0005 \mathrm{~g}$, and was set to stop when a change of $0.001 \mathrm{~g}$ per 99 seconds was reached and the total weight was recorded every 10 seconds. The moisture balance was set to rapid heat to the desired temperatures, which resulted in some overshoots in temperature control by a few degrees in the first minute and then remained at the set drying temperature $\pm 1^{\circ} \mathrm{C}$. Though it has a maximum capacity of $50 \mathrm{~g}$ a sample size of $10 \mathrm{~g}$ was used. This formed a single layer of woodchip on the $100 \mathrm{~mm} \varnothing$ pan, such that there was no interlocking stacking. The ambient temperature of the room where the experiments were conducted was in the range of $19^{\circ} \mathrm{C}$ to $21^{\circ} \mathrm{C}$, though this was found to have no discernible effect on the results of IR drying due to the enclosed chamber of the dryer. The drying temperatures were set to $50^{\circ} \mathrm{C}, 60^{\circ} \mathrm{C}, 70^{\circ} \mathrm{C}$ and $80^{\circ} \mathrm{C}$. The halogen heater had a heat duty of $400 \mathrm{~W}$ and logged the data via a bi-directional RS-232 cable connected to a laptop with appropriate data logging software.

$\mathrm{M}_{\mathrm{t}}$, was recorded after the original session stopped and saved to a file, the first mass recorded in this session was $\mathrm{M}_{0}$. So as to obtain the equilibrium value $\left(\mathrm{M}_{\mathrm{e}}\right)$ the balance was kept at the same settings, with the exception that the temperature which was set to $105^{\circ} \mathrm{C}$. The final mass value from this new setting was $\mathrm{M}_{\mathrm{e}}$ relating to the previous saved session.

Once $\mathrm{M}_{\mathrm{e}}$ was obtained the tested sample was then soaked in deionised water, by using a mesh bag, for 12 hours and drained for 5 minutes to reach the mass $\mathrm{M}_{0} \pm 0.5 \mathrm{~g}$ after draining. The drying procedure for the next set temperature was then repeated to obtain $\mathrm{M}_{t}$ and $\mathrm{M}_{\mathrm{e}}$ data for each set temperature.

\section{Results Analysis}

A fit to mathematical models for drying within Table 1 from experimental results for the moisture ratio has been evaluated using MATLAB and Non-linear Least Squares regression analysis. To identify the goodness of the fit commonly used statistical criteria were used; these include the sum of the square estimate errors (SSE), Equation 6, residual squared $\left(\mathrm{R}^{2}\right)$, Equation 7, and root mean squared error (RMSE), Equation 8, of the experimental results to the model equations.

$$
\begin{array}{r}
\mathrm{SSE}=\sum_{\mathrm{i}=1}^{\mathrm{n}}\left(\mathrm{MR}_{\mathrm{i}}-\widehat{\mathrm{MR}}_{\mathrm{l}}\right)^{2} \\
\mathrm{R}^{2}=1-\frac{\sum_{\mathrm{i}=1}^{\mathrm{n}}\left(\mathrm{MR}_{\mathrm{i}}-\widehat{\mathrm{MR}_{1}}\right)^{2}}{\sum_{\mathrm{i}=1}^{\mathrm{n}}\left(\mathrm{MR}_{\mathrm{i}}-\overline{\mathrm{MR}}_{\mathrm{l}}\right)^{2}} \\
\mathrm{RMSE}=\left[0.5 \sum_{\mathrm{i}=1}^{\mathrm{n}}\left(\mathrm{MR}_{\mathrm{i}}-\widehat{\mathrm{MR}}_{\mathrm{l}}\right)^{2}\right]^{0.5}
\end{array}
$$

\begin{tabular}{|c|c|c|c|c|c|c|c|}
\hline $\begin{array}{l}\text { Model } \\
\text { Number }\end{array}$ & Name & $\begin{array}{c}\text { Expression } \\
\operatorname{MR}(\mathrm{t})\end{array}$ & & $\begin{array}{l}\text { Model } \\
\text { Number }\end{array}$ & Name & $\begin{array}{c}\text { Expression } \\
\text { MR(t) }\end{array}$ & \\
\hline 1 & $\begin{array}{c}\text { Lewis/Newton } \\
\text { Model }\end{array}$ & $\mathrm{e}^{-\mathrm{at}}$ & [14] & 6 & Page & $\mathrm{e}^{-\mathrm{a} t^{\mathrm{b}}}$ & [15] \\
\hline 2 & $\begin{array}{l}\text { Henderson } \\
\text { and Pablis }\end{array}$ & $a e^{-b t}$ & [16] & 7 & Silva & $\mathrm{e}^{-\mathrm{at}-\mathrm{b} \sqrt{t}}$ & [17] \\
\hline 3 & Logorithmic & $a e^{-k t}+c$ & [18] & 8 & Diffusion & $a e^{-b t}+(1-a) e^{-b t}$ & [19] \\
\hline
\end{tabular}

These results show the goodness of fit to the models within Table 1 . The closer to $1 \mathrm{R}^{2}$ is and the smaller the SSE and RMSE values are the better the goodness of fit [13].

Table 1: Thin Layer Drying Models MR=f(t). 


\begin{tabular}{|c|c|c|c|c|c|c|c|}
\hline $\begin{array}{l}\text { Model } \\
\text { Number }\end{array}$ & Name & $\begin{array}{l}\text { Expression } \\
\operatorname{MR}(\mathrm{t})\end{array}$ & & $\begin{array}{l}\text { Model } \\
\text { Number }\end{array}$ & Name & $\begin{array}{c}\text { Expression } \\
\mathrm{MR}(\mathrm{t})\end{array}$ & \\
\hline 4 & $\begin{array}{l}\text { Wang and } \\
\text { Singh }\end{array}$ & $1+a t+b t^{2}$ & [20] & 9 & Verma & $a e^{-b t}+(1-a) e^{-c t}$ & [21] \\
\hline 5 & Peleg & $1-\left(\frac{t}{a+b t}\right)$ & [22] & 10 & $\begin{array}{l}\text { Two Term } \\
\text { Exponential }\end{array}$ & $a e^{-b t}+(1-a) e^{-b a t}$ & [23] \\
\hline
\end{tabular}

Incorporating influence of temperature into the 'Diffusion' and 'Page' models results in the equations in Table 2 [2]. The Page and Diffusion models were selected from those Table 1 based on the goodness of fit results to the models.

Table 2: Thin Layer Drying Models $\mathrm{MR}=\mathrm{f}(\mathrm{t}, \mathrm{T})$.

\begin{tabular}{|c|c|c|c|}
\hline $\begin{array}{l}\text { Model } \\
\text { Number }\end{array}$ & Expression MR(t,T) & $\begin{array}{l}\text { Model } \\
\text { Number }\end{array}$ & Expression MR(t,T) \\
\hline DM5 & $\left(\mathrm{aT}^{\mathrm{b}}\right) \mathrm{e}^{-\left(\mathrm{cT}^{\mathrm{d}}\right) \mathrm{t}}+\left(1-\mathrm{aT}^{\mathrm{b}}\right) \mathrm{e}^{-\left(\mathrm{c} \mathrm{T}^{\mathrm{d}}\right)\left(f \mathrm{~T}^{\mathrm{g}}\right) \mathrm{t}}$ & DM11 & $\left(\mathrm{ae}^{\mathrm{Tb}}\right) \mathrm{e}^{-\left(\mathrm{ce} \mathrm{e}^{\mathrm{Td}}\right) \mathrm{t}}+\left(1-\mathrm{ae}^{\mathrm{Tb}}\right) \mathrm{e}^{-\left(\mathrm{ce}^{\mathrm{Td}}\right)\left(f \mathrm{e}^{\mathrm{Tg}}\right) \mathrm{t}}$ \\
\hline DM6 & $\left(\mathrm{aT}^{\mathrm{b}}\right) \mathrm{e}^{-\left(\mathrm{cT}^{\mathrm{d}}\right) \mathrm{t}}+\left(1-\mathrm{aT}^{\mathrm{b}}\right) \mathrm{e}^{-\left(\mathrm{cT}^{\mathrm{d}}\right)\left(f \mathrm{e}^{\mathrm{Tg}}\right) \mathrm{t}}$ & $\begin{array}{l}\text { Page } \\
\text { DM1 }\end{array}$ & $e^{-\left(\mathrm{aT}^{\mathrm{b}}\right) \mathrm{t}^{\mathrm{ce}} \mathrm{Td}}$ \\
\hline DM7 & $\left(\mathrm{ae}^{\mathrm{Tb}}\right) \mathrm{e}^{-\left(\mathrm{cT}^{\mathrm{d}}\right) \mathrm{t}}+\left(1-\mathrm{ae}^{\mathrm{Tb}}\right) \mathrm{e}^{-\left(\mathrm{cT} \mathrm{T}^{\mathrm{d}}\right)\left(f \mathrm{e}^{\mathrm{Tg}}\right) \mathrm{t}}$ & $\begin{array}{l}\text { Page } \\
\text { DM2 }\end{array}$ & $e^{-\left(a T^{b}\right) t^{c T^{d}}}$ \\
\hline DM8 & $\left(\mathrm{aT}^{\mathrm{b}}\right) \mathrm{e}^{-\left(\mathrm{ce}^{\mathrm{Td}}\right) \mathrm{t}}+\left(1-\mathrm{aT}^{\mathrm{b}}\right) \mathrm{e}^{-\left(\mathrm{ce}^{\mathrm{Td}}\right)\left(f \mathrm{~T}^{\mathrm{g}}\right) \mathrm{t}}$ & $\begin{array}{l}\text { Page } \\
\text { DM3 }\end{array}$ & $e^{-\left(a e^{T b}\right) t^{c e^{T d}}}$ \\
\hline DM9 & $\left(\mathrm{aT}^{\mathrm{b}}\right) \mathrm{e}^{-\left(\mathrm{ce} \mathrm{T}^{\mathrm{Td}}\right) \mathrm{t}}+\left(1-\mathrm{aT}^{\mathrm{b}}\right) \mathrm{e}^{-\left(\mathrm{ce}^{\mathrm{Td}}\right)\left(f \mathrm{e}^{\mathrm{Tg}}\right) \mathrm{t}}$ & $\begin{array}{l}\text { Page } \\
\text { DM4 }\end{array}$ & $e^{-\left(a e^{T b}\right) t^{c T^{d}}}$ \\
\hline DM10 & $\left(\mathrm{ae}^{\mathrm{Tb}}\right) \mathrm{e}^{-\left(\mathrm{ce} \mathrm{e}^{\mathrm{Td}}\right) \mathrm{t}}+\left(1-\mathrm{ae}^{\mathrm{Tb}}\right) \mathrm{e}^{-\left(\mathrm{ce}^{\mathrm{Td}}\right)\left(f \mathrm{~T}^{\mathrm{g}}\right) \mathrm{t}}$ & & \\
\hline
\end{tabular}

\section{Rate of Mass Loss as a Function of Time Models}

The differentiation of the drying curve expressions was carried out with respect to time whilst assuming temperature is a constant variable.

Condensing the diffusion models by collating constant terms with respect to temperature to $\alpha, \beta$ and $\gamma$;

$$
\begin{gathered}
\text { MR }=\alpha \mathrm{e}^{-\beta \mathrm{t}}+(1-\alpha) \mathrm{e}^{-\beta \gamma \mathrm{t}} \\
\frac{\mathrm{dMR}}{\mathrm{dt}}=-\beta \alpha \mathrm{e}^{-\beta \mathrm{t}}-\beta \gamma(1-\alpha) \mathrm{e}^{-\beta \gamma \mathrm{t}}
\end{gathered}
$$

The Page models to;

$$
\begin{gathered}
\mathrm{MR}=\mathrm{e}^{-\alpha \mathrm{t}^{\beta}} \\
\frac{d M R}{d t}=-\alpha \beta t^{\beta-1} e^{-\alpha t^{\beta}}
\end{gathered}
$$

Where $\alpha, \beta$ and $\gamma$ are defined for each model in Table 3 .

To convert these to rates of mass loss over time;

\begin{tabular}{|c|c|c|c|c|c|c|c|}
\hline Model Number & $\alpha$ & $\beta$ & $\gamma$ & Model Number & $\alpha$ & $\beta$ & $\gamma$ \\
\hline DM5 & $\left(\mathrm{aT}^{\mathrm{b}}\right)$ & $\left(\mathrm{cT}^{\mathrm{d}}\right)$ & $\left(\mathrm{eT}^{\mathrm{g}}\right)$ & DM11 & $\left(\mathrm{ae}^{\mathrm{Tb}}\right)$ & $\left(c e^{T d}\right)$ & $\left(f \mathrm{e}^{\mathrm{Tg}}\right)$ \\
\hline DM6 & $\left(\mathrm{aT}^{\mathrm{b}}\right)$ & $\left(\mathrm{cT}^{\mathrm{d}}\right)$ & $\left(f \mathrm{e}^{\mathrm{Tg}}\right)$ & Page DM1 & $\left(\mathrm{aT}^{\mathrm{b}}\right)$ & $\left(c e^{T d}\right)$ & \\
\hline DM7 & $\left(a e^{T b}\right)$ & $\left(\mathrm{cT}^{\mathrm{d}}\right)$ & $\left(f \mathrm{e}^{\mathrm{Tg}}\right)$ & Page DM2 & $\left(\mathrm{aT}^{\mathrm{b}}\right)$ & $\left(\mathrm{cT}^{\mathrm{d}}\right)$ & \\
\hline DM8 & $\left(\mathrm{aT}^{\mathrm{b}}\right)$ & $\left(c e^{T d}\right)$ & $\left(\mathrm{eT}^{\mathrm{g}}\right)^{\prime}$ & Page DM3 & $\left(a e^{T b}\right)$ & $\left(c e^{T d}\right)$ & \\
\hline DM9 & $\left(\mathrm{aT}^{\mathrm{b}}\right)$ & $\left(c e^{T d}\right)$ & $\left(f \mathrm{e}^{\mathrm{Tg}}\right)$ & Page DM4 & $\left(a e^{T b}\right)$ & $\left(\mathrm{cT}^{\mathrm{d}}\right)$ & \\
\hline DM10 & $\left(a e^{T b}\right)$ & $\left(\mathrm{ce}^{\mathrm{Td}}\right)$ & $\left(\mathrm{eT}^{\mathrm{g}}\right)^{\prime}$ & & & & \\
\hline
\end{tabular}

$$
A W_{D}=\left|\left(M_{0}-M_{e}\right)\left(\frac{d M R}{d t}\right)\right|
$$

Table 3: Condense Diffusion and Page Model Coefficients. 


\section{Results and Discussion}

At different temperatures the moisture ratio variation with time is shown in Figure 1. The moisture ratio of the woodchip decreased as the drying time increased. The drying time decreased as temperature increased within the working range.

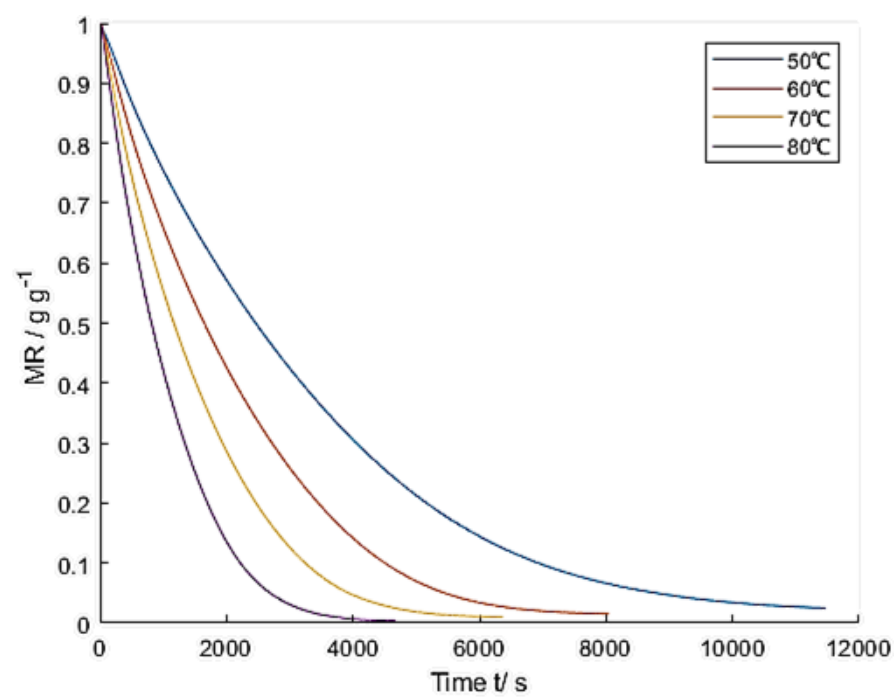

Fig. 1: Moisture Ratio vs Time Results.

Analysis of Table 4 shows that for $50{ }^{\circ} \mathrm{C}, 60{ }^{\circ} \mathrm{C}, 70{ }^{\circ} \mathrm{C}$ and $80{ }^{\circ} \mathrm{C}$ models $1-10$ resulted in $\mathrm{R}^{2}$ values ranging from 0.9737 to 0.9993 , RMSE from 0.00738 to 0.0440 , and SSE from 0.0288 to 0.9364 . The models from Table 1 following exponential trends are found to have a better fit than the polynomial and fractional terms (models 4 and 5). The model that has the least goodness of fit was the second order polynomial. With the exception of the polynomial model all of the model's analyses showed an $\mathrm{R}^{2}$ value of over 0.98 . All the models had a low RMSE showing a small standard deviation of results from the models. From Table 4 the Page model had the best fit though the Diffusion Model is a widely used model [24]. These were therefore selected to be used for the adapted temperature inclusive models [2].

Table 4: Statistical analysis Results for Modelling Moisture Content Individual Temperatures.

\begin{tabular}{|c|c|c|c|c|c|c|c|c|c|c|c|}
\hline \multirow{2}{*}{\multicolumn{2}{|c|}{ Model }} & \multicolumn{4}{|c|}{ Temperature } & \multicolumn{2}{|c|}{ Model } & \multicolumn{4}{|c|}{ Temperature } \\
\hline & & 50 & 60 & 70 & 80 & & & 50 & 60 & 70 & 80 \\
\hline \multirow[t]{3}{*}{1} & $\mathrm{R}^{2}$ & 0.9958 & 0.9969 & 0.9975 & 0.9974 & 6 & $\mathrm{R}^{2}$ & 0.9993 & 0.9988 & 0.9992 & 0.9992 \\
\hline & RMSE & 0.01754 & 0.01517 & 0.01346 & 0.01379 & & RMSE & 0.00738 & 0.00945 & 0.00777 & 0.00787 \\
\hline & SSE & 0.3525 & 0.1849 & 0.1151 & 0.0886 & & SSE & 0.06236 & 0.07156 & 0.03826 & 0.02882 \\
\hline \multirow[t]{3}{*}{2} & $\mathrm{R}^{2}$ & 0.9972 & 0.9985 & 0.9988 & 0.9980 & 7 & $\mathrm{R}^{2}$ & 0.9983 & 0.9987 & 0.9990 & 0.9990 \\
\hline & RMSE & 0.01441 & 0.01044 & 0.00920 & 0.01202 & & RMSE & 0.01108 & 0.00984 & 0.00869 & 0.00860 \\
\hline & SSE & 0.2378 & 0.0874 & 0.0537 & 0.0672 & & SSE & 0.1407 & 0.0777 & 0.0479 & 0.0345 \\
\hline \multirow[t]{3}{*}{3} & $\mathrm{R}^{2}$ & 0.9988 & 0.9984 & 0.9985 & 0.9983 & 8 & $\mathrm{R}^{2}$ & 0.9921 & 0.9884 & 0.9887 & 0.9854 \\
\hline & RMSE & 0.00928 & 0.01092 & 0.01062 & 0.01131 & & RMSE & 0.02407 & 0.02956 & 0.02871 & 0.03281 \\
\hline & SSE & 0.09854 & 0.09569 & 0.07145 & 0.05949 & & SSE & 0.6628 & 0.7018 & 0.5234 & 0.5017 \\
\hline \multirow[t]{3}{*}{4} & $\mathrm{R}^{2}$ & 0.9888 & 0.9874 & 0.9784 & 0.9737 & 9 & $\mathrm{R}^{2}$ & 0.9958 & 0.9952 & 0.9960 & 0.9954 \\
\hline & RMSE & 0.02860 & 0.03077 & 0.03968 & 0.04401 & & RMSE & 0.01755 & 0.01906 & 0.01707 & 0.01839 \\
\hline & SSE & 0.9364 & 0.9364 & 0.7595 & 0.9026 & & SSE & 0.3525 & 0.2916 & 0.1850 & 0.1576 \\
\hline \multirow[t]{3}{*}{5} & $\mathrm{R}^{2}$ & 0.9927 & 0.9912 & 0.9940 & 0.9921 & 10 & $\mathrm{R}^{2}$ & 0.9958 & 0.9930 & 0.9939 & 0.9921 \\
\hline & RMSE & 0.02314 & 0.02574 & 0.02103 & 0.02420 & & RMSE & 0.01758 & 0.02293 & 0.02100 & 0.02417 \\
\hline & SSE & 0.6132 & 0.5320 & 0.2803 & 0.2728 & & SSE & 0.3539 & 0.4226 & 0.2804 & 0.2727 \\
\hline
\end{tabular}




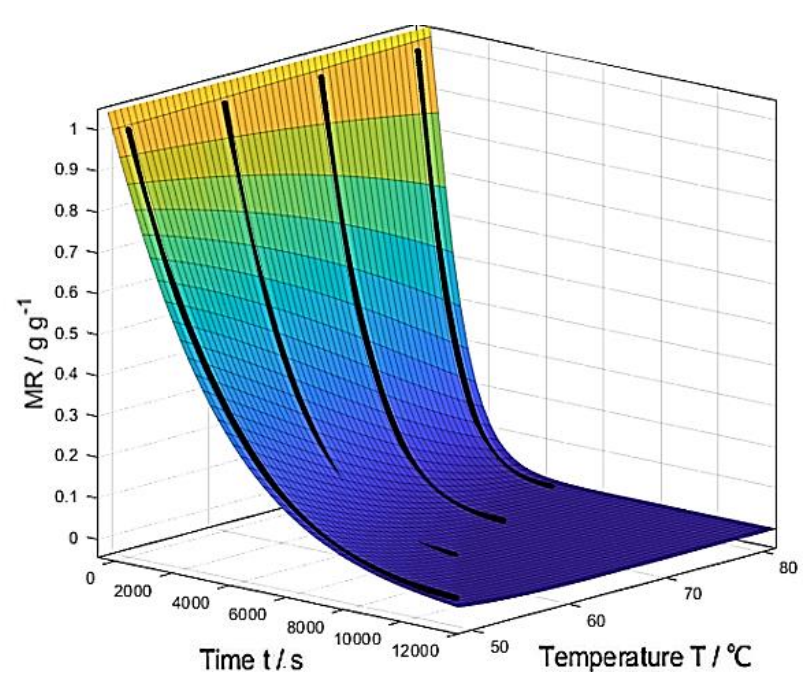

Fig. 2: Moisture Ratio vs Time Data at Temperatures Measured Against DM5 Plot.

Page and diffusion models including temperature were fitted to the four experimental moisture ratio vs time profiles, using MATLAB non-liner regression curve fitting. An example of this can be seen in Figure 2. Table 5 illustrates the resulting $\mathrm{R}^{2}$ values of these models which have a range between 0.9975-0.9989. The model with the best fit is DM11. The $\mathrm{R}^{2}$ values within Table 4 are comparable to those within [2] for the carrot drying. These results show a better goodness of fit for both the Page and Diffusion models with the same quantity of data and temperature increments used. Comparatively the results from Gypsum drying [6] also showed a wider range of $\mathrm{R}^{2}$ values for the same models.

Table 5: Statistical analysis Results for Modelling Moisture Content Temperature Dependent.

\begin{tabular}{cccccccccccc}
\hline $\begin{array}{c}\text { Fit } \\
\text { Name }\end{array}$ & SSE & $\mathrm{R}^{2}$ & DFE & RMSE & Coefficients & $\begin{array}{c}\text { Fit } \\
\text { Name }\end{array}$ & SSE & $\mathrm{R}^{2}$ & DFE & RMSE & Coefficients \\
\hline DM5 & 0.5702 & 0.9975 & 3051 & 0.01367 & 6 & DM1 & 0.2424 & 0.9989 & 3051 & 0.008914 & 6 \\
DM6 & 0.4438 & 0.9980 & 3051 & 0.01206 & 6 & $\begin{array}{c}\text { Page } \\
\text { DM1 }\end{array}$ & 0.2849 & 0.9987 & 3053 & 0.009660 & 4 \\
DM7 & 0.4392 & 0.9981 & 3051 & 0.01200 & 6 & $\begin{array}{c}\text { Page } \\
\text { DM2 }\end{array}$ & 0.3983 & 0.9982 & 3053 & 0.01142 & 4 \\
DM8 & 0.2991 & 0.9987 & 3051 & 0.009902 & 6 & $\begin{array}{c}\text { Page } \\
\text { DM3 }\end{array}$ & 0.2861 & 0.9987 & 3053 & 0.009680 & 4 \\
DM9 & 0.3018 & 0.9987 & 3051 & 0.009946 & 6 & $\begin{array}{c}\text { Page } \\
\text { DM4 }\end{array}$ & 0.2666 & 0.9988 & 3053 & 0.009345 & 4 \\
DM10 & 0.5073 & 0.9978 & 3051 & 0.01289 & 6 & & & & & & \\
\hline
\end{tabular}

Plots of $\mathrm{W}_{\mathrm{D}} \mathrm{A}=\mathrm{f}(\mathrm{T}, \mathrm{t})$, Figure 3, show a peak in rate of mass loss vs time, with the rate decreasing from around 570 seconds for $50^{\circ} \mathrm{C}$ and 230 seconds for $80^{\circ} \mathrm{C}$, less than half the time. Figure 3 shows the highest $\mathrm{AW}_{\mathrm{D}}$ value for $80{ }^{\circ} \mathrm{C}$. This is $60 \%$ higher than that at $50{ }^{\circ} \mathrm{C}$. These results are concordant with those from high moisture paddy IR drying [25] which also show a peak in drying rate at around 240 seconds and kiwi fruit showing a peak in rate for convective IR drying at under 25 minutes for $40-55^{\circ} \mathrm{C}[26]$.

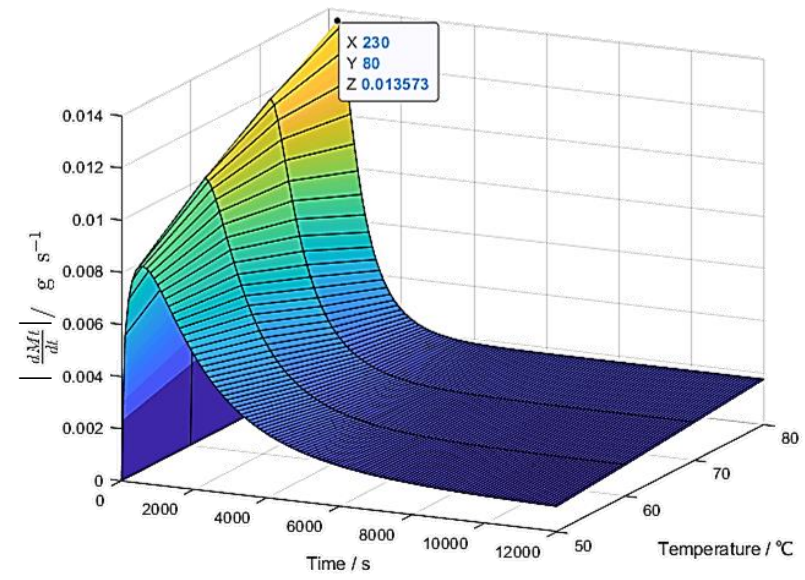

Fig. 3: $\left|\mathrm{dM}_{\mathrm{t}} / \mathrm{dt}\right|$ vs Time Plot for $50-80^{\circ} \mathrm{C}$. 
The results show that the evaporation of water from the surface area is characterised by the rapid initial drying period, and as liquid water within the pores started diffusing out, a falling rate period was reached with the rate decreasing as surface moisture depleted. The IR drying radiated water molecules within the woodchip water quickly producing vapour within the chip as well as at the surface of the solid (i.e from the surface water). Therefore there was not a large time frame at which the drying rate is significantly controlled by evaporation of surface moisture. This surface evaporative drying creates a constant drying rate regime, which is therefore independent of internal mechanisms within the solid and is surface area dependent. For a constant drying rate a flat rate would be shown rather than a peak. Plotting MR vs $A W_{D}$ further supports this. Interestingly, within Figure 4, the rates crossed a second time with the rate of depletion in $\mathrm{AW}_{\mathrm{D}}$ for the lower temperature slower, though the peak is lower. The initial spike of surface mass loss was therefore detrimental to rates of mass loss at the lower end of moisture content as the rate of diffusion through the woodchip was a lot slower than the loss of surface moisture.

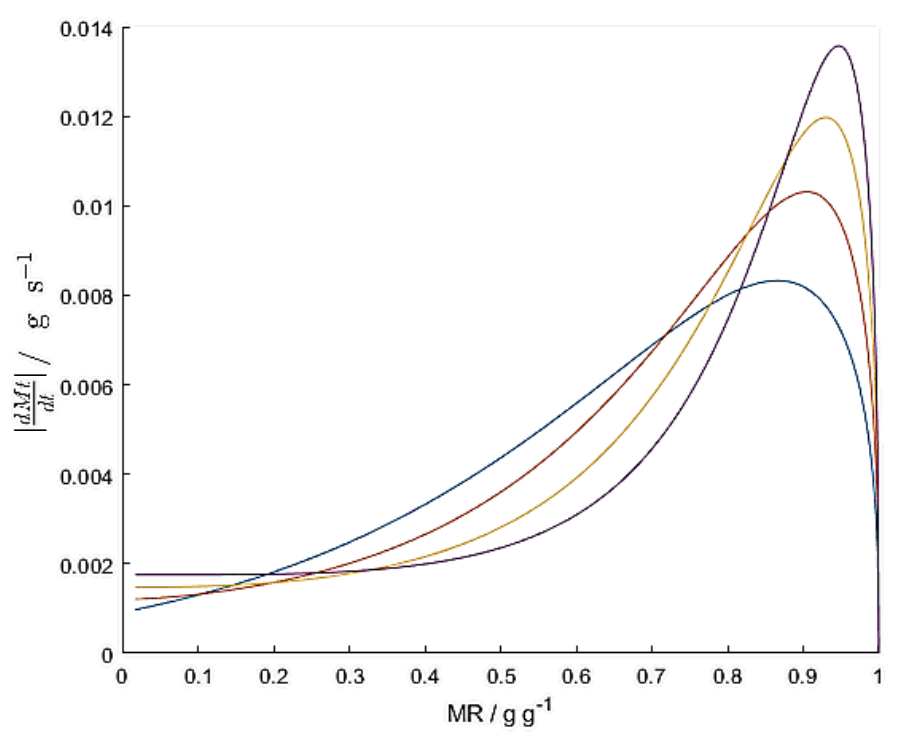

Fig.4: $\left|\mathrm{dM}_{\mathrm{t}} / \mathrm{dt}\right|$ vs MR Plot for Measured Temperatures 50, 60, 70 and $80^{\circ} \mathrm{C}$.

The highest temperature was the fastest to reach a rate of $0.001 \mathrm{~g}$ per 99 seconds as well as the closest to the equilibrium weight of all tests, as shown by Table 5 . The starting weight after the $50^{\circ} \mathrm{C}$ test increased by almost $0.3 \mathrm{~g}$ after a $105^{\circ} \mathrm{C}$ final weight was gathered. This is likely due to volatiles driven off at this temperature, pore size increasing during the removal of water and orientation of the chips means water gathered in crevices. The final weights after $105^{\circ} \mathrm{C}$ drying are consistent within a $0.03 \mathrm{~g}$ range.

Table 6: Drying Characteristics.

\begin{tabular}{lrlrl}
\hline Temperature & Drying Rate Period & $\mathrm{M}_{0}$ & $\mathrm{M}_{\mathrm{DT}}$ & $\mathrm{M}_{\mathrm{e}}$ \\
\hline $50^{\circ} \mathrm{C}$ & $3 \mathrm{hr} 12 \mathrm{~min}$ & 10.562 & 4.714 & 4.565 \\
$60^{\circ} \mathrm{C}$ & $2 \mathrm{hr} 13 \mathrm{~min}$ & 10.839 & 4.668 & 4.574 \\
$70^{\circ} \mathrm{C}$ & $1 \mathrm{hr} 47 \mathrm{~min}$ & 10.869 & 4.61 & 4.548 \\
$80^{\circ} \mathrm{C}$ & $1 \mathrm{hr} 18 \mathrm{~min}$ & 10.861 & 4.587 & 4.563 \\
\hline
\end{tabular}

\section{Conclusions}

For four temperatures the effect of temperature on behaviour of IR drying of woodchip was investigated. The drying regimes and behaviours of mass loss over time were identified. Models where compared using SSE, RSME and $\mathrm{R}^{2}$ values, Two of these models have reflected well temperature dependency, confirming use and validation of model assumptions (i.e. symmetric uniform distribution of moisture within the initial sample, constant diffusion coefficient, negligible shrinkage of woodchips, and instantaneous evaporation at the surface).

Key Findings

- Drying of the same $\sim 10 \mathrm{~g}$ sample of woodchip took a maximum of $3 \mathrm{hr} 12 \mathrm{~min}$ and a minimum of $1 \mathrm{hr} 18 \mathrm{~min}$ at 50 to $80^{\circ} \mathrm{C}$

- Moisture loss was described well by the Page and Diffusion models using temperature as a second dependent variable. 
- Differentiating the fitted models produced rate of mass loss data, which was extrapolated along temperatures ranging from $50-80^{\circ} \mathrm{C}$.

- A peak in drying rate was observed in all data measured with the sharpness of the peak decreasing with temperature.

- A constant rate drying period was not observed, due to the sizable rise in rate of mass loss. There was not a lengthy time period for which the drying rate was significantly controlled by evaporation of surface moisture.

\section{Highlights and Limitations}

The final masses of the sample reached were within a $0.03 \mathrm{~g}$ range, $0.7 \%$ of the smallest $\mathrm{M}_{\mathrm{e}}$. Drying time was less than half when increasing the temperature by $30^{\circ} \mathrm{C}$ from $50^{\circ} \mathrm{C}$.

The variation in chip produced makes prediction of drying of woodchip for large scale difficult as characteristics of wood vary greatly from bark to wood of different chip sizes.

\section{Recommendations}

Furthering this study, diffusion coefficients and activation energy can be calculated from singular pieces of chip of known thickness L.

Using the in Equation 14 model by Crank [27].

$$
M R=\frac{M_{t}-M_{e}}{M_{0}-M_{e}}=\frac{8}{\pi^{2}} \sum_{n=0}^{\infty} \frac{1}{(2 n+1)^{2}} e^{-(2 n+1)^{2}\left(\frac{\pi^{2} D_{L}}{L^{2}}\right) t}
$$

For long drying times;

$$
M R=\frac{M_{t}-M_{e}}{M_{0}-M_{e}}=\frac{8}{\pi^{2}} e^{-\left(\frac{\pi^{2} D_{L}}{L^{2}}\right) t}
$$

With results used to predict mass losses from differing thicknesses as well as at different temperatures.

\section{Acknowledgements}

This work is supported by the Centre for Global Eco Innovation and the ERDF. Woodchip used is credited to Bowland Bioenergy Ltd with which this work is presented in partnership. Special thanks to industry advisors, Anne Seed and Mike Ingoldby, and for providing laboratory space, Dr John Crosse.

\section{References}

[1] Gebreegziabher, T., A. Oyedun, and D. Hui, Optimum biomass drying for combustion - A modeling approach Energy, 2013. 53: p. 67-73.

[2] Toğrul, H., Suitable drying model for infrared drying of carrot. Journal of Food Engineering, 2006. 77(3): p. 610619.

[3] Bruce, D.M., Exposed-layer barley drying: Three models fitted to new data up to $150^{\circ} \mathrm{C}$. Journal of Agricultural Engineering Research, 1985. 32(4): p. 337-348.

[4] Sarimeseli, A. and M. Yuceer, Investigation Of Infrared Drying Behaviour Of Spinach Leaves Using ANN Methodology And Dried Product Quality. Chemical and Process Engineering, 2015. 36: p. 425-436.

[5] Da Silva, W.P., Silva, C.M.D.P.S. Gama, F.J.A., and Gomes, J.P. Mathematical models to describe thin-layer drying and to determine drying rate of whole bananas. Journal of the Saudi Society of Agricultural Sciences, 2014. 13(1): p. 67-74.

[6] A. Endruweit and A. C. Long, "Analytical permeability modelling for 3D woven reinforcements," ICCM Int. Conf. Compos. Mater., 2009.

[7] Pillai, M.G., Thin layer drying kinetics, characteristics and modeling of plaster of paris. Chemical Engineering Research and Design, 2013. 91(6): p. 1018-1027.

[8] Erbay, Z. and F. Icier, A Review of Thin Layer Drying of Foods: Theory, Modeling, and Experimental Results. Critical reviews in food science and nutrition, 2010. 50: p. 441-64

[9] Crank, J. and E.P.J. Crank, The Mathematics of Diffusion. 1979: Clarendon Press.p 3-4

[10] British Standards Institution (2017) BS EN ISO 18134-2:2017: Solid biofuels. Determination of moisture content. Oven dry method. Total moisture. Simplified method. Available at: bsol-bsigroup-com 
[11] Gavhane, K., Unit Operations-II. 2014: Nirali Prakashan.

[12] British Standards Institution (2016) BS EN ISO 17827-1:2016 Solid biofuels. Determination of particle size distribution for uncompressed fuels. Oscillating screen method using sieves with apertures of $3,15 \mathrm{~mm}$ and above. Available at: bsol-bsigroup-com

[13] Reddy, T.A., Applied Data Analysis and Modeling for Energy Engineers and Scientists. 2011: Springer US.

[14] Lewis. 1921, The drying of Solid Materials. J Indian Eng 5:p427-443

[15] Heldman, D.R., Encyclopedia of Agricultural, Food, and Biological Engineering (Print). 2003: Taylor \& Francis.p238

[16] Henderson, S.M. and S. Pabis, Grain drying theory: I. Temperature effect on drying coefficient. J. Agric. Engng. Res., 1961. 6.

[17] W.P. Silva, C.M.D.P.S. Silva, J.A.R. Sousa, and V.S.O. Farias Empirical and diffusion models to describe water transport into chickpea (Cicer arietinum L.) International Journal of Food Science and Technology 2012,

[18] Yagcioglu A. Degirmencioglu A, Cagatay F, Drying Characteristics of Laurel Leaves Under Different Drying Conditions. In: Procedings of the $7^{\text {th }}$ international Congress on Agricultural Mechanization and Energy:p 565-569

[19] Kassem AS, Comparative Studies on Thin Layer Drying Models For Wheat, Procedings for the International Cogress on Agricultural Engineering, 1998: p 2-6

[20] Wang, G.Y. and R.P. Singh, Single Layer Drying Equation For Rough Rice. 1978.

[21] Verma LR, Bucklin RA, Edna JB, and Wratten FT, Effects of Drying Air Parameter Drying Models, 1985: p296301

[22] Peleg, M.. An empirical model for the description of moisture sorption curves. Journal of Food Science, $1988 \mathrm{p}$ $53,1216-1217,1219$

[23] Henderson SM, Progress in developing the thin layer drying equation. 1974:p1167-1172

[24] Erbay, Z. and F. Icier, A Review of Thin Layer Drying of Foods: Theory, Modeling, and Experimental Results. Critical reviews in food science and nutrition, 2010. 50: p. 441-64.

[25] Das, I., S.K. Das, and S. Bal, Drying kinetics of high moisture paddy undergoing vibration-assisted infrared (IR) drying. Journal of Food Engineering, 2009. 95(1): p. 166-171.

[26] Özdemir, M.B., Aktaş, M., Şevik, S., Khanlari, A. Modeling of a convective-infrared kiwifruit drying process. International Journal of Hydrogen Energy, 2017. 42(28): p. 18005-18013.

[27] Crank, J. and E.P.J. Crank, The Mathematics of Diffusion. 1979: Clarendon Press. 